\section{Modifying the gluten-free threshold for foods: first do no harm}

To THE EDITOR: The gluten-free (GF) diet for people with coeliac disease (CD) is complex, costly, and compliance with the diet is variable. Coeliac Australia, with the Australian Food and Grocery Council, are lobbying to increase the mandated gluten threshold for GF foods. ${ }^{1}$ The situation in Australia since 1995 has been that there must be "no detectable gluten" in foods labelled "gluten free". The proposed new standard is " $<20$ parts per million (ppm)". This has been proposed because food testing has become increasingly sensitive over the years, resulting in fewer foods being considered gluten free. The current detection level of food testing is about $3 \mathrm{ppm}$. Unfortunately, the proposed new GF standard may not be safe for patients with $\mathrm{CD}$.

There are few high-quality studies determining a safe gluten intake for patients with $C D$, although it is known that tolerable amounts vary between patients. ${ }^{2}$ In one study, 42 patients with $\mathrm{CD}$ who were eating a GF diet received 0,10 or $50 \mathrm{mg}$ of gluten daily for 3 months $(10 \mathrm{mg}$ in $500 \mathrm{~g}$ of food represents $20 \mathrm{ppm}$; $10 \mathrm{mg}$ gluten is ingested in $1 / 250$ th of a slice of bread containing $2.5 \mathrm{~g}$ gluten). Patients' duodenal mucosa were examined histologically before and after the gluten challenge. The study concluded that, for patients with $\mathrm{CD}$, the daily dietary intake of gluten should be $<50 \mathrm{mg} .{ }^{3}$ This study has been interpreted as suggesting that $10 \mathrm{mg}$ of gluten daily is safe. ${ }^{1}$ Regrettably, the patients in the study were a selective group, possibly less sensitive to gluten and, of those receiving $10 \mathrm{mg}$ of gluten daily, one had symptomatic relapse and several showed worsening $\mathrm{CD}$ on histological examination. ${ }^{3}$ It is therefore surprising this study has been particularly influential in recommending a GF standard of $<20$ ppm. $^{1}$

In 2011, a comprehensive United States Food and Drug Administration (FDA) safety report concluded that gluten levels in food of $<1 \mathrm{ppm}$ are required to protect the greatest number of patients with $\mathrm{CD}^{4}{ }^{4}$ Despite this, a long-awaited FDA ruling, released on 2 August 2013, sets the GF standard at $<20 \mathrm{ppm} .{ }^{5}$ This formalises tighter standards than previously existed in the US. Establishing a standard is complex, requiring consideration of issues such as industry and consumer concerns, industry regulation, economics, international precedent and safety.

The concept of doing no harm in health care is paramount. In Australia, where concerns about the availability of GF foods have been raised, ${ }^{1}$ it may be prudent to allow GF foods an increase in "measurable" gluten (eg, from undetectable to $<1-3 \mathrm{ppm}$ ). By contrast, increasing the "permissible" level of gluten (from undetectable to $<20 \mathrm{ppm}$ ) will increase overall gluten ingestion in a GF diet. For an undetermined proportion of patients with $C D$, this will lead to adverse health outcomes and generate additional health care costs.

Geoffrey M Forbes Gastroenterologist

Royal Perth Hospital, Perth, WA. geoff.forbes@health.wa.gov.au

Competing interests: No relevant disclosures. Online first 12/08/13

doi: 10.5694/mjal3.10922

1 Coeliac Society of Australia. Submission dated 25 July 2008. Melbourne: Australian Government Productivity Commission. 2008. http://www.pc. gov.au/_data/assets/pdf_file/0008/82286/ sub046.pdf (accessed Aug 2013).

2 Akobeng AK, Thomas AG. Systematic review: tolerable amount of gluten for people with coeliac disease. Aliment Pharmacol Ther 2008; 27: 1044-1052.

3 Catassi C, Fabiani E, lacono G, et al. A prospective, double blind, placebo-controlled trial to establish a safe gluten threshold for patients with celiac disease. Am J Clin Nutr 2007; 85: 160-166.

4 Office of Food Safety, Center of Food Safety and Applied Nutrition, Food and Drug Administration. Health hazard assessment for gluten exposure in individuals with celiac disease: determination of tolerable daily intake levels and levels of concern for gluten, May 2011. http://www.fda.gov/ downloads/Food/FoodScienceResearch/ UCM264152.pdf (accessed Jul 2013).

5 United States Food and Drug Administration. FDA defines "gluten free" for food labelling [media release]. 2 Aug 2013. http://www.fda.gov/ NewsEvents/Newsroom/PressAnnouncements/ ucm363474.htm (accessed Aug 2013). 